\title{
Twice Daily Compared to Three Times Daily Hydrocortisone in Prepubertal Children with Congenital Adrenal Hyperplasia
}

\author{
Jennifer Apsan ${ }^{a}$ Charlene Thomas $^{b}$ Hailan Elnaas ${ }^{a}$ Karen Lin-Su ${ }^{a}$ \\ Oksana Lekarev ${ }^{\mathrm{a}}$ \\ ${ }^{a}$ Division of Pediatric Endocrinology, Department of Pediatrics, Weill Cornell Medicine, New York Presbyterian \\ Hospital, New York, NY, USA; 'D Division of Biostatistics and Epidemiology, Weill Cornell Medicine, New York, NY, USA
}

\section{Keywords}

Glucocorticoids · Congenital adrenal hyperplasia ·

Prepubertal growth · Metabolic impacts

\begin{abstract}
Introduction: Glucocorticoid therapy in children with congenital adrenal hyperplasia $(\mathrm{CAH})$ must be finely balanced between optimizing adrenal control and minimizing side effects. Twice (BID) rather than three times daily (TID) hydrocortisone may provide similar adrenal control and reduce metabolic risk. We compared BID and TID regimens with respect to adrenal control, growth, and metabolic effects. Methods: A retrospective chart review ( $n=128$ visits, 36 individual patients) of prepubertal children with classical $\mathrm{CAH}$ was conducted at a tertiary care center between March 2007 and February 2020. Adrenal control, growth, and metabolic data were extracted in those taking hydrocortisone BID versus TID. Univariate generalized estimating equations models were performed to analyze the effect of dose frequency on outcomes of interest. Results: Overall, we found no difference in adrenal control ( $8 \%$ vs. $18 \%$ poor control) or testosterone levels ( $9.65 \mathrm{ng} / \mathrm{dL}$ vs. $7.62 \mathrm{ng} / \mathrm{dL}$ ) between the BID versus TID groups. We detected no difference in growth velocity (6.86 vs. $6.32 \mathrm{~cm} /$ year) or bone age advancement (11.3
\end{abstract}

vs. 5.91 months) between the groups. There was no difference in daily steroid dose (12.1 vs. $11.7 \mathrm{mg} / \mathrm{m}^{2} /$ day), BMI Zscore $(0.43$ vs. 0.31$)$, or systolic blood pressure percentile (65.5 vs. 61.7). Conclusion: BID dosing provides similar adrenal control and does not appear to impact growth or bone age advancement. On the other hand, TID dosing does not appear to increase the metabolic side effect profile in this age-group. Dosing should be patient-centered with individualized consideration.

(c) 2022 The Author(s)

Published by S. Karger AG, Basel

\section{Introduction}

Congenital adrenal hyperplasia $(\mathrm{CAH})$ refers to a group of inherited adrenocortical enzyme deficiencies. The most common form is 21-hydroxylase (P450c21) deficiency, which causes insufficient mineralocorticoid and glucocorticoid production, leading to a subsequent increase in androgen production $[1,2]$. The enzyme deficiency occurs on a spectrum; patients with classical CAH have a more severe enzyme deficiency while patients with nonclassical CAH have a milder enzyme defect [3]. Even within classical CAH, there is a spectrum of enzyme activity in which, children with salt-wasting $\mathrm{CAH}$ present with

Correspondence to:

Jennifer Apsan, jennydeluty@gmail.com

Karger@karger.com www.karger.com/hrp

Karger $\stackrel{\text { ' }}{5}$

BOPEN ACCESS
(C) 2022 The Author(s)

Published by S. Karger AG, Basel

This is an Open Access article licensed under the Creative Commons Attribution-NonCommercial-4.0 International License (CC BY-NC) (http://www.karger.com/Services/OpenAccessLicense), applicable to the online version of the article only. Usage and distribution for commercial purposes requires written permission. 
both a glucocorticoid and mineralocorticoid deficiency, while those with simple-virilizing CAH have primarily a glucocorticoid deficiency $[1,3,4]$. The lack of cortisol synthesis in classical CAH results in adrenal insufficiency that necessitates daily glucocorticoid replacement. It is particularly important in times of physiologic illness or stress, during which an increased stress-dose level of glucocorticoid treatment is typically warranted. The mineralocorticoid deficiency in salt-wasting $\mathrm{CAH}$ can present with hyponatremia and hyperkalemia as early as $5-7$ days of life. Treatment includes daily fludrocortisone. Additional sodium replacement is often needed until about 1 year of age, at which point dietary intake is typically sufficient to provide daily sodium requirements [5]. In classical CAH, precursors of adrenal metabolites are shunted to the androgen pathway, causing increased production of testosterone and androstenedione. Signs of excess androgen production may include atypical genitalia in 46, XX individuals, acne, hirsutism, alopecia, premature pubarche, early epiphyseal fusion leading to poor adult height outcome, menstrual cycle irregularities, and impaired fertility $[1,3,4]$.

Hydrocortisone is the mainstay of treatment for children with $\mathrm{CAH}$ [4]. It has been proven to optimize adrenal control while having the least growth suppressive impact on the pediatric patient [6]. Supraphysiologic glucocorticoid dosing lowers adrenal androgen production by suppressing ACTH. The aims of treatment are to not only replace cortisol but to also minimize excess adrenal androgen production, thereby optimizing growth, adult height prognosis, appropriate onset of puberty, menstrual cycles, and fertility. However, chronically, high-dose glucocorticoid treatment in the pediatric population may lead to a Cushingoid appearance and growth suppression. Late-onset metabolic effects, such as obesity, insulin resistance, hypertension, hyperlipidemia, atrial fibrillation, and venous thromboembolism, are also seen in adult patients with $\mathrm{CAH}[7,8]$. It is critical that management of $\mathrm{CAH}$ be balanced with known risks of prolonged steroid treatment in the pediatric population.

The Endocrine Society published CAH guidelines in 2010 , with an update in 2018, that have proposed glucocorticoid dosing. Data show that hydrocortisone should be given in tablet form as hydrocortisone suspension is inadequate to provide a good level of adrenal control secondary to nonuniform distribution of medication in liquid $[4,9]$. Guidelines also caution providers against doses exceeding $20 \mathrm{mg} / \mathrm{m}^{2} /$ day in infants or $15-17 \mathrm{mg} / \mathrm{m}^{2} /$ day in children secondary to concerns of growth suppression [4]. The guidelines state that hydrocortisone should be dosed three times daily (TID) in growing children and 2-3 times daily as maintenance in fully grown patients. A recent study has found that TID hydrocortisone is the most common pediatric CAH regimen globally [10]. However, there is no cited evidence for the superiority of TID over two times daily (BID) dosing of hydrocortisone in children. Our institution has used BID dosing of hydrocortisone as a therapeutic option for children with $\mathrm{CAH}$ for decades, finding that the convenience of this regimen helps patient compliance and that biochemical $\mathrm{CAH}$ parameters as well as clinical parameters of growth, clinical hyperandrogenism, and metabolic risk are well controlled with this regimen [11-13]. We hypothesized that exposure to BID rather than TID hydrocortisone could reduce the total daily steroid dose and, in turn, reduce metabolic risk factors while still maintaining adequate adrenal control. Moreover, ease of administration could also lead to improved treatment consistency and compliance.

\section{Materials and Methods}

A retrospective chart review ( $n=128$ office visits of 36 individual children) of prepubertal children with classical CAH was conducted at a CAH comprehensive care center at a large New York City medical center between March 2007 and February 2020. Data were extracted from one annual comprehensive visit each year between the age of 4 years to the onset of puberty. The onset of puberty was defined by either a pediatric $\mathrm{LH} \geq 0.3 \mathrm{IU} / \mathrm{L}$ or clinical exam findings of Tanner 2 breasts in females or $4 \mathrm{~cm}^{3}$ testes in males. Some patients had multiple visits analyzed while others had only one, depending on when care was initiated at our center and when the onset of puberty occurred. One representative annual visit in which a bone age was completed was chosen to capture metabolic, growth, and adrenal endpoints. At each visit, we compared testosterone levels, androstenedione levels, annualized growth velocity (AGV), bone age, blood pressure, BMI, and total daily steroid dose in those taking glucocorticoids BID $(n=77)$ versus TID $(n=51)$. Bloodwork was obtained in the morning approximately $2 \mathrm{~h}$ after the morning hydrocortisone dose. AGV was measured as the difference in growth between annual visits with associated bone age and was annualized to a full 12-month period if the visits were not exactly 12 months apart. Bone age advancement was calculated as bone age minus chronological age. Annual adrenal control in both groups was also captured based on multiple 17-hydroxyprogesterone (17OHP) levels measured at visits throughout each year. Adrenal control was defined as follows for each year: good control was defined as $17 \mathrm{OHP}<1,000 \mathrm{ng} / \mathrm{dL}$, at least $75 \%$ of the time. Moderate control was defined as $17 \mathrm{OHP}$ $<1,000 \mathrm{ng} / \mathrm{dL}$ more than $25 \%$ and less than $75 \%$ of the time. Poor adrenal control was defined as $17 \mathrm{OHP}<1,000 \mathrm{ng} / \mathrm{dL}$, less than or equal to $25 \%$ of the time. IRB exemption approval status was granted by the Weill Cornell Medicine Institutional Review Board for retrospective review of de-identified data under exception requirements HHS 45 CFR 46.104(d). Informed consent requirements 
Table 1. Baseline characteristics of BID and TID hydrocortisone groups

\begin{tabular}{lllc}
\hline Characteristic & $\begin{array}{l}\text { BID at the first visit } \\
(n=20)^{1}\end{array}$ & $\begin{array}{l}\text { TID at the first visit } \\
(n=15)^{1}\end{array}$ & $p$ value $^{2}$ \\
\hline $\begin{array}{l}\text { Gender, } n(\%) \\
\quad \text { Female }\end{array}$ & $14(70)$ & $11(73)$ & $>0.9$ \\
$\quad$ Male & $6(30)$ & $4(27)$ & 0.6 \\
$\begin{array}{l}\text { Age at the first visit } \\
\text { Type of CAH, } n(\%)\end{array}$ & $6.00(5.00,7.00)$ & $7.00(5.50,8.00)$ & 0.5 \\
$\quad \begin{array}{l}\text { SV CAH } \\
\text { SW CAH }\end{array}$ & $7(35)$ & $3(20)$ & 0.3 \\
Visits, $n$ & $13(65)$ & $12(80)$ & $2(1,5)$ \\
\hline
\end{tabular}

${ }^{1} N(\%) ;$ median (IQR). ${ }^{2}$ Fisher's exact test; Wilcoxon rank sum test.
Table 2. Comparison between BID and TID dosing regimens

\begin{tabular}{|c|c|c|c|}
\hline & $\mathrm{BID}(n=77)$ & $\operatorname{TID}(n=51)$ & $p$ value \\
\hline Total daily $\mathrm{HC}$ dose, $\mathrm{mg} / \mathrm{m}^{2} /$ day & 12.1 & 11.7 & 0.194 \\
\hline \multicolumn{4}{|l|}{ Adrenal control, $n(\%)$} \\
\hline Good/fair & $70(92)$ & $41(82)$ & \multirow{2}{*}{0.107} \\
\hline Poor & $6(7.9)$ & $9(18)$ & \\
\hline \multicolumn{4}{|l|}{ Androgens } \\
\hline Testosterone & 9.65 & 7.62 & 0.442 \\
\hline Androstenedione & 40.2 & 22.5 & 0.041 \\
\hline \multicolumn{4}{|l|}{ Growth parameters } \\
\hline $\mathrm{AGV}, \mathrm{cm} / \mathrm{yr}$ & 6.86 & 6.32 & 0.186 \\
\hline Bone age advancement, months & 11.3 & 5.91 & 0.380 \\
\hline \multicolumn{4}{|l|}{ Metabolic parameters } \\
\hline BMI Z-score & 0.43 & 0.31 & 0.479 \\
\hline Systolic BP, \%ile & 65.5 & 61.7 & 0.451 \\
\hline Diastolic BP, \%ile & 64.3 & 53.7 & 0.018 \\
\hline
\end{tabular}

* $p$ values were calculated using GEE modeling. were waived as well under IRB approval. Univariate generalized estimating equation models were performed to understand the effect of dose frequency on our outcomes of interest. Due to the potential correlation between visits from the same patient, generalized estimating equation modeling was utilized. The models assumed an exchangeable correlation structure as we expected within-subject observations to be equally correlated. However, using an auto-regressive correlation structure also yielded similar results. All $p$ values are two-sided with statistical significance evaluated at the 0.05 alpha level. All analyses were performed in R 4.0.5 (R Core Team, Vienna, Austria).

\section{Results}

There were no statistically significant baseline differences between the BID and TID groups (Table 1) (Table 1). When analyzing biochemical parameters, there was no difference in adrenal control (92\% good/fair con- trol vs. $82 \%$ good/fair control) or testosterone levels (9.65 ng/dL vs. $7.62 \mathrm{ng} / \mathrm{dL}$ ) between those taking hydrocortisone BID versus TID. Around $18 \%$ of subjects taking hydrocortisone TID had poor adrenal control compared with $7.9 \%$ of subjects taking hydrocortisone BID. However, this did not reach statistical significance $(p=0.1)$ (Table 2). Higher androstenedione levels were observed in the BID group than the TID group (40.2 ng/dL vs. 22.5 ng/dL, $p<0.05$ ) (Table 2). When looking at growth parameters in the BID compared to the TID group, there were no significant differences in AGV (6.86 vs. $6.32 \mathrm{~cm}$ per year) or bone age advancement (11.3 vs. 5.91 months) (Table 2). We were not able to detect a difference in total daily steroid doses between those taking BID versus TID hydrocortisone (12.1 vs. $11.7 \mathrm{mg} / \mathrm{m}^{2} /$ day) in prepubertal children being treated for CAH (Table 2). When analyzing metabolic parameters, we were unable to detect a difference in the BMI $Z$-score ( 0.43 vs. 0.31 ) or systolic blood 
pressure percentiles (65.5\%ile vs. $61.7 \%$ ile, $p=0.451$ ) between BID and TID groups. A difference in diastolic blood pressure parameters was noted (64.3\%ile vs. $53.7 \%$ ile, $p<0.05)$, though both groups maintained normal diastolic blood pressure percentiles for age (Table 2).

\section{Discussion}

Current standard of care guidelines support the use of daily glucocorticoids in the treatment of classical CAH. Dosage must be finely balanced to prevent adrenal crisis and excess androgen production while also allowing for optimization of linear growth and development [4]. There is a scarcity of studies looking into BID dosing regimens and its impact on the efficacy of adrenal control and its side effect profile. Overall, we have found that hydrocortisone dosing BID may be as effective in terms of biochemical adrenal control and clinical outcomes of growth compared to TID regimens. At the same time, we have demonstrated that patients who were on TID dosing were not on a higher steroid dose than those on BID dosing and did not have more metabolic compromise in the short term.

Although we did not detect a statistically significant difference in adrenal control between those taking hydrocortisone BID versus TID, it should be noted that a higher percentage of those taking hydrocortisone TID had poor control than those taking it BID. A possible explanation is that some of those patients may not have consistently taken their mid-day dose, effectively reducing their total daily hydrocortisone [14]. It should be noted that compliance was not evaluated as part of this study design, and thus, no definitive conclusions can be drawn. It is also possible that by giving some of the total daily steroid in the afternoon (when 17OHP may be naturally lower), it precludes the clinician from giving a higher dose at bedtime or early morning, which could more effectively suppress the innate early morning rise of ACTH-driven $17 \mathrm{OHP}$ and androgen production $[13,15]$. This warrants further investigation.

We did not find any steroid sparing effect with taking hydrocortisone BID instead of TID as total daily steroid doses were similar in both groups. It should however be noted that the subset of patients at our institution who are on TID dosing are given a very low mid-day dose rather than evenly divided doses. Our institution's preference after infancy is to give a higher dose at bedtime to combat the overnight ACTH surge, thereby optimizing adrenal androgen suppression [16]. This regimen is different from those institutions that may choose to evenly divide hydro-

Glucocorticoid Regimens in CAH cortisone TID or to administer the lowest dose at bedtime. It is possible that dividing TID dosing evenly may lead to higher total daily doses and different metabolic outcomes.

As the total daily steroid dose did not differ statistically between the BID and TID groups, it is not surprising that there were no noted metabolic differences between groups. Current guidelines advise not to exceed hydrocortisone dose of $20 \mathrm{mg} / \mathrm{m}^{2} /$ day in infants or 15-17 mg/ $\mathrm{m}^{2} /$ day in children [4]. On average, patients in both our BID and TID regimen groups met this recommendation with mean daily steroid doses of $12.1 \mathrm{mg} / \mathrm{m}^{2} /$ day and 11.7 $\mathrm{mg} / \mathrm{m}^{2} /$ day, respectively. Of note, these doses are both lower than the average dose of $14.2 \mathrm{mg} / \mathrm{m}^{2}$ reported for children ages 6 to onset of puberty in a large European cohort of $14.2 \mathrm{mg} / \mathrm{m}^{2}$ in those taking hydrocortisone TID [17]. One limitation of this study is that its retrospective nature only allowed for data collected over 13 years. The literature in the adult data show that $\mathrm{CAH}$ patients are at increased risk of obesity, hypertension, and insulin resistance $[7,8]$. We cannot comment on future metabolic impacts that may become evident after puberty as a result of long-term steroid therapy or puberty itself.

In our study, no difference was detected with respect to adrenal control based on $17 \mathrm{OHP}$ levels or with respect to testosterone levels. A small decrease in androstenedione was noted in the TID group. It remains unclear if this is clinically relevant as this biochemical parameter did not translate into any meaningful clinical differences in growth velocity or bone age advancement.

Current guidelines further note that "insufficient data exist to recommend fractional distribution of doses throughout the day or empiric dosing in the very early morning hours" $[4,18]$. Still, TID hydrocortisone is recommended for growing patients, whereas 2-3 times daily hydrocortisone is recommended for fully grown patients [4].

Pharmacokinetics of hydrocortisone and diurnal variation of adrenal products are also essential to consider when understanding optimal dosing intervals. There is remarkable synchronicity in the patterns of ACTH, 17OHP, and androstenedione production, peaking at about 4-10 a.m. [19]. There tends to be a decline in hormones in the afternoon regardless of when hydrocortisone is given [13].

There is also a large physiologic range of half-life for hydrocortisone, which varies greatly from patient to patient. One study has proposed a mean half-life of $76.5 \pm$ 5.2 min with a remarkably large range of $40-225.3 \mathrm{~min}$ and a clearance of hydrocortisone of $578.5 \pm 1,100.6 \mathrm{~mL} /$ min [20]. Thus, patients may have levels of hydrocortisone remaining for longer than expected, albeit not at 
peak levels. The residual hydrocortisone during the middle of the day may in fact be sufficient to maintain adequate adrenal control. Furthermore, studies of diurnal variation show lowest natural 17OHP levels between the hours of 1,600-2,000 [13, 15]. Dauber et al. [19] has shown that some patients have a natural decline of $17 \mathrm{OHP}$ in the afternoon prior to any dose of $\mathrm{HC}$ being given. Therefore, adding another hydrocortisone dose at this time with another peak may be physiologically unnecessary [15]. Other studies show that overall 17OHP may be unaffected, regardless of hydrocortisone regimens once, BID, or TID [13].

It is also important to note that there is significant variability in adrenal hormone production depending on time of day, physical activity, daily stressors, and individual patient variability $[16,19]$. As it is impractical to obtain multiple blood draws throughout the day in clinical practice, there must be some acknowledgment of fluctuation in $17 \mathrm{OHP}$ and androgen levels $[19,21]$. In fact, levels may fluctuate through the day as much as 40-fold [19], and steady state cortisol levels are not only very difficult to obtain [22] but are also not physiologic. Thus, clinical parameters of overall well-being, growth, bone age, and metabolic parameters remain the most important indicators of optimal treatment. These parameters are arguably more important than maintaining continuous steady state cortisol levels and suppressed androgens throughout the entire day. Our study is unique in its ability to highlight that BID dosing does not appear to impair any growth or metabolic parameters in children with $\mathrm{CAH}$.

Limitations to our study include its single-center and retrospective nature. The retrospective nature of this review limited our ability to understand important information such as dosing compliance. If patients on TID dosing only took their medication BID, this may have impacted our results. We also reviewed a relatively small number of patients. Multicenter collaborative efforts will be needed to better understand the interplay of dosing distribution and timing of dosing on adrenal, growth, and metabolic parameters.

In conclusion, we have shown that there is no clear advantage to TID over BID hydrocortisone dosing in the treatment of prepubertal children with $\mathrm{CAH}$. With regards to adrenal control, BID dosing does not appear to detract from overall adrenal control biochemically nor does it appear to impact growth or bone age advancement. On the other hand, patients on TID dosing are not on a higher glucocorticoid dose compared to patients on BID dosing. In addition, prepubertal children on TID hydrocortisone do not have apparent adverse outcomes with regard to metabolic parameters. Dosing regimens should therefore be patient-centered with consideration of individual schedules and the family's ability to consistently take the medication as prescribed.

\section{Acknowledgments}

The authors thank the Comprehensive Care Center for Congenital Adrenal Hyperplasia at Weill Cornell Medicine for its support of this patient database and manuscript. The authors acknowledge the important work of Katherine Foote in data input and analysis.

\section{Statement of Ethics}

IRB exemption approval status was granted by the Weill Cornell Medicine Institutional Review Board for retrospective review of de-identified data under exception requirements HHS 45 CFR 46.104(d). Informed consent requirements were waived as well under IRB approval.

\section{Conflict of Interest Statement}

Karen Lin-Su, MD, is the Medical Director of the CARES (Congenital Adrenal Hyperplasia Research Education and Support) Foundation. Oksana Lekarev, DO, is on the Medical Advisory Board of the CARES Foundation.

\section{Funding Sources}

No external funding was required for the completion of this study.

\section{Author Contributions}

Jennifer Apsan made substantial contributions in the conception, design, extraction of data, and interpretation of data analysis. Jennifer Apsan drafted the manuscript. Karen Lin-Su and Oksana Lekarev made substantial contributions in the conception and design of the study, analysis of data interpretation, and editing the manuscript. Charlene Thomas has made substantial contributions in data analysis and editing of the manuscript. Hailan Elnaas made substantial contributions in data collection and review of the manuscript. All the authors approved the final submitted version and agreed to be accountable for the accuracy and integrity of the work.

\section{Data Availability Statement}

The data that support the findings of this study are openly available at https://doi.org/10.6084/m9.figshare.19179143.v1.
Apsan/Thomas/Elnaas/Lin-Su/Lekarev 


\section{References}

1 Speiser PW, White PC. Congenital adrenal hyperplasia. N Engl J Med. 2003 Aug 21; 349(8):776-88.

2 White PC, New MI, Dupont B. HLA-linked congenital adrenal hyperplasia results from a defective gene encoding a cytochrome P-450 specific for steroid 21-hydroxylation. Proc Natl Acad Sci U S A. 1984 Dec;81(23):7505-9.

3 Witchel SF. Congenital adrenal hyperplasia. J Pediatr Adolesc Gynecol. 2017 Oct;30(5): 520-34.

4 Speiser PW, Arlt W, Auchus RJ, Baskin LS, Conway GS, Merke DP, et al. Congenital adrenal hyperplasia due to steroid 21-hydroxylase deficiency: an endocrine society clinical practice guideline. J Clin Endocrinol Metab. 2018 Nov 1;103(11):4043-88.

5 Gomes LG, Madureira G, Mendonca BB, Bachega TA. Mineralocorticoid replacement during infancy for salt wasting congenital adrenal hyperplasia due to 21-hydroxylase deficiency. Clinics. 2013;68(2):147-52.

6 Khadilkar VV, Khadilkar AV, Maskati GB. Impact of availability of oral hydrocortisone on growth of children with $\mathrm{CAH}$. Indian J Pediatr. 2005;72:301-3.

7 Tamhane S, Rodriguez-Gutierrez R, Iqbal AM, Prokop LJ, Bancos I, Speiser PW, et al. Cardiovascular and metabolic outcomes in congenital adrenal hyperplasia: a systematic review and meta-analysis. J Clin Endocrinol Metab. 2018 Sep 28;103(11):4097-103.

8 Kim MS, Merke DP. Cardiovascular disease risk in adult women with congenital adrenal hyperplasia due to 21-hydroxylase deficiency. Semin Reprod Med. 2009 Jul;27(4):316-21.
9 Merke DP, Cho D, Calis KA, Keil MF, Chrousos GP. Hydrocortisone suspension and hydrocortisone tablets are not bioequivalent in the treatment of children with congenital adrenal hyperplasia. J Clin Endocrinol Metab. 2001 Jan;86(1):441-5.

10 Bacila I, Freeman N, Daniel E, Sandrk M, Bryce J, Ali SR, et al. International practice of corticosteroid replacement therapy in congenital adrenal hyperplasia: data from the ICAH registry. Eur J Endocrinol. 2021 Apr; 184(4):553-63.

11 New M, Yau M, Lekarev O, Lin-Su K, Parsa A, Pina C, et al. Congenital adrenal hyperplasia; 2015.

12 Nimkarn S, Gangishetti PK, Yau M, New MI. 21-hydroxylase-deficient congenital adrenal hyperplasia; 2016.

13 Winterer J, Chrousos GP, Loriaux DL, Cutler GB Jr. Effect of hydrocortisone dose schedule on adrenal steroid secretion in congenital adrenal hyperplasia. J Pediatr. 1985 Jan;106(1): $137-42$.

14 Zadik Z. The cost of non-compliance in congenital adrenal hyperplasia. J Pediatr Endocrinol Metab. 2009 Dec;22(12):1093-4.

15 Charmandari E, Matthews DR, Johnston A, Brook CG, Hindmarsh PC. Serum cortisol and 17-hydroxyprogesterone interrelation in classic 21-hydroxylase deficiency: is current replacement therapy satisfactory? J Clin Endocrinol Metab. 2001 Oct;86(10):4679-85.

16 Schröder MAM, van Herwaarden AE, Span PN, van den Akker ELT, Bocca G, Hannema $\mathrm{SE}$, et al. Optimizing the timing of highest hydrocortisone dose in children and adolescents with 21-hydroxylase deficiency. J Clin Endocrinol Metab. 2021 Nov 12.
17 Hoyer-Kuhn H, Huebner A, Richter-Unruh A, Bettendorf M, Rohrer T, Kapelari K, et al. Hydrocortisone dosing in children with classic congenital adrenal hyperplasia: results of the German/Austrian registry. Endocr Connect. 2021 May 19;10(5):561-9.

18 German A, Suraiya S, Tenenbaum-Rakover Y, Koren I, Pillar G, Hochberg Z. Control of childhood congenital adrenal hyperplasia and sleep activity and quality with morning or evening glucocorticoid therapy. J Clin Endocrinol Metab. 2008 Dec;93(12):4707-10.

19 Dauber A, Feldman HA, Majzoub JA. Nocturnal dexamethasone versus hydrocortisone for the treatment of children with congenital adrenal hyperplasia. Int J Pediatr Endocrinol. 2010 Sep 14;2010:347636.

20 Hindmarsh PC, Charmandari E. Variation in absorption and half-life of hydrocortisone influence plasma cortisol concentrations. Clin Endocrinol. 2015 Apr;82(4):557-61.

21 Debono M, Mallappa A, Gounden V, Nella AA, Harrison RF, Crutchfield CA, et al. Hormonal circadian rhythms in patients with congenital adrenal hyperplasia: identifying optimal monitoring times and novel disease biomarkers. Eur J Endocrinol. 2015 Dec; 173(6):727-37.

22 Melin J, Parra-Guillen ZP, Michelet R, Truong T, Huisinga W, Hartung N, et al. Pharmacokinetic/pharmacodynamic evaluation of hydrocortisone therapy in pediatric patients with congenital adrenal hyperplasia. J Clin Endocrinol Metab. 2020 Mar 1;105(3): dgaa071. 